\title{
Mesures et modélisation de la résistance stomatique foliaire et de la transpiration d'un couvert de tomates de serre.
}

\author{
T Boulard, A Baille, M Mermier, F Villette \\ INRA, Station de Bioclimatologie, BP 9184143 Montfavet Cedex, France
}

(Reçu le 21 août 1990; accepté le 8 mars1991)

\begin{abstract}
Résumé - L'évolution de la transpiration d'une culture de tomates de serre a été suivie en période estivale et analysée par le biais de mesures :

- de la résistance stomatique foliaire (faces inférieure et supérieure), mesurée à différents étages du couvert;

- de l'indice foliaire;

- des principaux facteurs climatiques : rayonnement, température de l'air et du couvert à différents étages, déficit de saturation.

Un modèle d'estimation de la résistance du couvert aux transferts d'eau en fonction des facteurs climatiques est proposé et discuté. Ce modèle est ensuite utilisé dans une procédure permettant de calculer la transpiration à l'échelle du couvert.

La comparaison entre les sorties du modèle de transpiration et les mesures réalisées à l'aide d'un lysimètre montre que la prise en compte du couvert de tomate sous la forme d'une seule strate disposée en rangs, caractérisée par un rayonnement moyen absorbé et une résistance équivalente du couvert, permet d'estimer avec une précision satisfaisante la transpiration à l'échelle horaire d'un couvert de tomates sous serre. Une utilisation opérationnelle, moyennant certaines études complémentaires, pourrait être envisagée dans le cadre du contrôle de l'irrigation et du climat sous serre.
\end{abstract}

\section{Lycopersicon esculentum = tomate $/$ résistance stomatique $/$ transpiration}

Summary - Measurement of stomatal resistance and transpiration in a greenhouse tomato canopy. Comparison between a 1-layer and a multi-layer model. Transpiration for a greenhouse soilless tomato crop was determined with an electronic balance during summer periods and analyzed with simultaneous measurements of:

- leaf stomatal resistances (both lower and upper faces), measured at 3 levels inside the canopy (figs 2, 3 and 4);

- leaf temperature (fig 3);

- leaf area index;

- main interior climatic parameters: global radiation, air temperature, vapour pressure deficit.

A simple method for estimating the canopy resistance $\mathrm{r}_{\mathrm{s}}$ to water vapour transfer from climate parameters was put forward on the basis of the multiplicative model proposed by Jarvis (1976). It was shown that $\mathrm{r}_{\mathrm{s}}$ is primarily dependent upon solar radiation level, $\mathrm{G}_{\mathrm{o}}$ (fig 6 ) and that residuals can be taken into account by either vapour pressure deficit, $\mathrm{D}$, or temperature (air or leaf temperature). Comparison between a 1-layer model and a multilayer model was carried out, and showed that the 2 models gave similar values for computed values of $r_{s}$.

The 1-layer estimations of $r_{s}$ were used to determine canopy transpiration course by mean of:

- the direct formula, with calculation of the air-leaf vapour pressure deficit from leaf surface temperature data;

- the combination method (Penman-Monteith formula), with estimation of the radiation absorbed by the canopy.

Calculated and measured hourly transpiration values (fig 9) showed a better agreement when using the combination method (fig 10) than when using the direct method. Partition of the total transpiration flux between the radiative component and the advective component (fig 11) was discussed. It was concluded that the advective term including the influence of vapour pressure deficit cannot be neglected in the case of greenhouse conditions, and that it is necessary for irrigation and climate control purposes to take into account this parameter, in order to improve short-term predictions for canopy transpiration.

Lycopersicon esculentum $=$ tomato $/$ stomatal resistance $/$ transpiration 


\section{INTRODUCTION}

Sous serre, les cultures hors-sol se développent actuellement de manière rapide (Blanc, 1987), tant en cultures maraîchères (tomate, concombre) qu'en cultures florales (gerbera, rosier). Les serristes en ont une maîtrise relativement satisfaisante, mais certains points demandent cependant à être améliorés. C'est le cas de la gestion de l'irrigation, qui doit se faire de manière très précise, du fait de la faible rétention en eau des substrats utilisés (tourbe-pouzzolane, laine de roche, etc.). Une connaissance précise des pertes par évapotranspiration est nécessaire.

Stanghellini (1987) a étudié de manière approfondie la transpiration de cultures de tomate en Europe septentrionale (Pays-Bas), où les conditions climatiques hivernales et estivales sont très différentes de celles que l'on rencontre dans les pays du pourtour méditerranéen (Sud de la France, Espagne, Grèce, etc.). Dans ces régions, notamment au printemps et en été, les brusques variations de temps et les fortes chaleurs induisent des conditions climatiques sous serre qui sont difficilement maîtrisables et qui peuvent entraîner des variations importantes dans la demande climatique en eau. Les fortes températures, supérieures à $30^{\circ} \mathrm{C}$, et les déficits de saturation élevés ( $>20 \mathrm{mbar}$ ) peuvent couramment survenir pendant plusieurs $h$ au cours de journées ensoleillées de mai jusqu'en septembre. Une fermeture stomatique et un ralentissement de la transpiration des plantes se produisent alors, aggravant encore la situation climatique dans les serres, puisque la transpiration du couvert est la principale source de refroidissement et d'humidification de la serre (Boulard, 1985).

Dans les systèmes modernes de pilotage du climat et de l'irrigation, la précision du calcul du flux de transpiration est indispensable si l'on désire mieux gérer le climat et l'irrigation sous serre. C'est dans cet objectif que nous avons entrepris la mise au point d'un modèle simple de transpiration sous serre qui réponde aux critères suivants :

- pouvoir être facilement rendu opérationnel, et pour cela, être compatible, du point de vue des entrées, avec les 3 paramètres climatiques (température et humidité de l'air, rayonnement solaire) qui sont mesurés dans les serres équipées d'un système informatisé de gestion du climat;

- permettre le calcul de la transpiration pour l'ensemble du couvert, considéré comme formant une seule strate.
Ces 2 critères nécessitent une adaptation, voire une simplification des modèles de transpiration développés pour les cultures de plein air (Chen, 1984, Katerji et Perrier, 1985; Lhomme et Katerji, 1988; Choudhury et Monteith, 1988);

- enfin, le modèle doit prendre en compte les caractéristiques particulières du microclimat des serres, qui diffère, sur un certain nombre de points, du climat extérieur. Ainsi, les gradients verticaux de température et d'humidité à l'intérieur du couvert sont faibles (Yang et al, 1989) et peuvent être négligés. Cette simplification conforte l'approche des modélisateurs physiques qui ne considèrent qu'un seul paramètre de température et d'humidité pour caractériser l'ensemble du volume d'air de la serre (Kano et Sadler, 1985). On pourra aussi considérer, en première approximation, que le rayonnement reçu par la culture est entièrement diffus (diffusion par les parois de la serre : Gratraud et al, 1986; Tchamitchian, 1990). Enfin, sauf accidents culturaux, nous considérerons que la fertilisation et l'irrigation ne sont pas limitantes.

Cet article présente tout d'abord les principaux résultats expérimentaux obtenus lors de 2 campagnes de mesure dans 2 sites du Sud de la France (Alenya, près de Perpignan, et Montfavet, près d'Avignon). Après analyse de ces résultats, un modèle de transpiration est proposé et validé sur un certain nombre de journées caractéristiques de la période estivale.

\section{MATÉRIELS ET MÉTHODES}

\section{Serres et cultures}

Dans les 2 sites, les serres utilisées étaient similaires: serre bi-chapelle à couverture plastique, de $400 \mathrm{~m}^{2}$ de superficie, équipée de systèmes de climatisation couramment employés par les serristes : chauffage à base température (substrat et atmosphère), ouvrants en toiture, écran thermique utilisé comme écran d'ombrage en été.

Les variétés de tomates choisies étaient des variétés à croissance indéterminée (Perfecto à Alenya, Duranto à Montfavet), cultivées en hors sol, sur substrat tourbe-pouzzolane, avec une densité d'environ 2,5 plants $/ \mathrm{m}^{2}$. Les plantations ont été réalisées fin décembre-début janvier.À l'époque des mesures (maijuin), ces cultures étaient en pleine production. L'irrigation et la nutrition minérale étaient réalisées simultanément, par un système de goutte à goutte, le tout étant géré par un automate de fertirrigation, basé sur le calcul de l'ETP serre à partir du rayonnement global extérieur. 


\section{Instrumentation de mesures et recueil des données}

À quelques détails près, les mesures réalisées sur les 2 sites expérimentaux sont similaires. À côté des mesures climatiques classiques (températures d'air et de substrat, hygrométrie de l'air, rayonnement solaire intérieur et extérieur, rayonnement net sous abri, vitesse et direction de vent), un soin plus particulier a été apporté à la mesure de la température de feuillage, $T_{f}$. Celle-ci a été réalisée avec des thermocouples très fins, piqués dans la feuille au niveau de la nervure centrale du foliole terminal (fig 1). Les mesures ont été faites à 3 niveaux de végétation $(0,5 \mathrm{~m}, 1,2 \mathrm{~m}$ et 1,9 $\mathrm{m})$ avec à chaque niveau 4 thermocouples dont les valeurs étaient ensuite moyennées pour obtenir une température représentative du niveau considéré.

Parrallèlement à ces mesures physiques, des mesures de résistance stomatique sur les 2 faces des feuilles ont été réalisées de manière discontinue, à l'aide d'un poromètre (MK3, Delta Device). Les échantillonnage ont porté sur des feuilles situées au même niveau que les thermocouples. Chaque mesure est le résultat d'un échantillonnage portant sur 8 mesures individuelles réalisées sur des feuilles situées au même étage et ne recevant pas de rayonnement direct. L'indice foliaire $(L A I)$ a été déterminé aux dates les plus proches possibles des mesures de résistance et de transpiration, au moyen de la procédure décrite en annexe 1. Les mesures de transpiration ont été réalisées

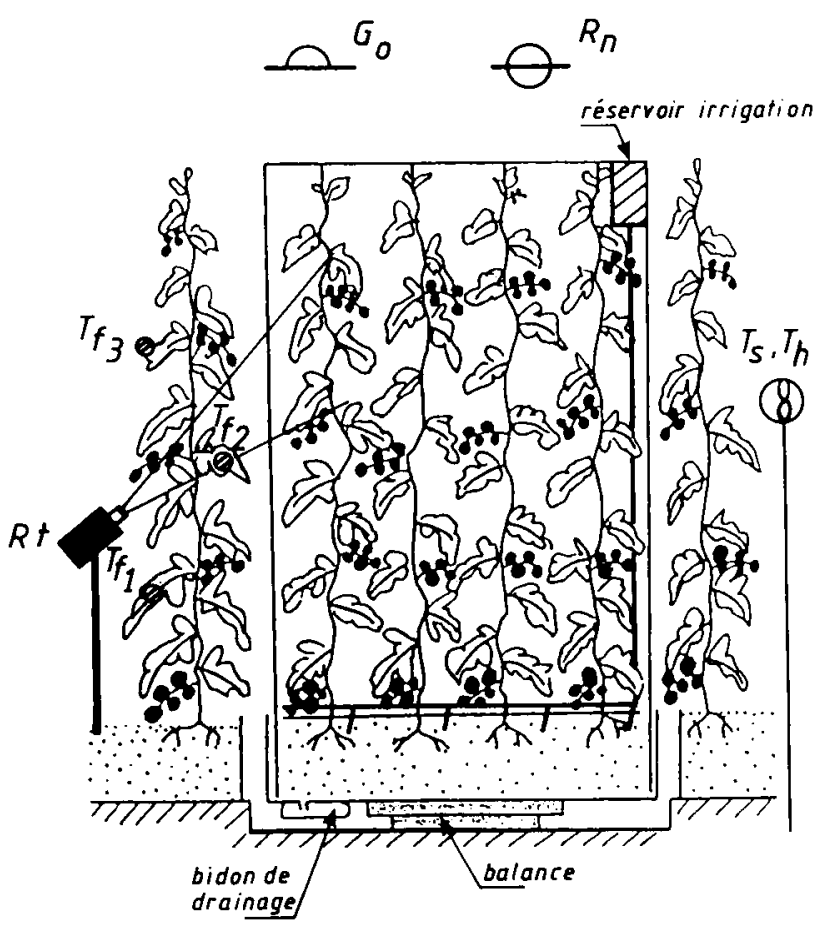

Fig 1. Schéma des installations de mesures lysimétriques et climatiques installées sous les serres. $R_{t}:$ radiothermomètre infrarouge; $G_{0}$ : pile de rayonnement global située au-dessus de la culture; $R_{n}$ : pyrradiomètre différentiel situé au-dessus de la culture; $T_{s}, T_{h}$ : psychromètre; $T_{f 1}, T_{f 2}, T_{f 3}$ : mesures de températures de feuille situées à 3 étages du couvert $(0,5 \mathrm{~m}, 1,2 \mathrm{~m}, 1,9 \mathrm{~m})$. à l'aide d'un lysimètre implanté dans la continuité d'un rang de culture (fig 1) et supportant, soit 3 plantes (essais d'Alenya), soit 4 plantes (essais de Montfavet). Le lysimètre est constitué d'une balance électronique (marque Sauter), ayant une résolution de $1 \mathrm{~g}$ pour une portée de $120 \mathrm{~kg}$, sur laquelle sont disposés un chassis supportant le substrat et un portique assurant le tuteurage des plants. Deux réservoirs d'eau (pour l'irrigation et le drainage) sont également solidaires du chassis. Si on néglige l'évaporation du substrat, que l'on peut considérer comme très faible (à cause du film de plastique qui le recouvre) et l'accroissement en poids sec des plantes, la diminution du poids de l'ensemble ainsi formé correspond à la perte par transpiration des plantes de tomate portées par le chassis.

\section{RÉSULTATS}

\section{Modèles de résistance stomatique foliaires}

Des mesures préliminaires de résistance stomatique ayant mis en évidence d'importantes variations suivant la face de la feuille et la profondeur dans le couvert, nous avons étudié en premier lieu ces 2 champs de variation.

Les mesures ponctuelles du rapport $A=r_{s, s} /$ $r_{s, i}$, où $r_{s, s}$ et $r_{s, i}$ sont respectivement les résistances stomatiques de la face supérieure et de la face inférieure de feuilles issues des niveaux $0,5 \mathrm{~m}$ et $1,2 \mathrm{~m}$, sont représentées sur la fig 2 .

Ce rapport, voisin de 1 pendant la nuit, augmente progressivement au cours de la journée et atteint une valeur maximale de l'ordre de 3 pour les rayonnements incidents élevés $\left(G_{0}\right.$, rayonnement global incident au sommet de la culture, de l'ordre de 300 W.m-2).

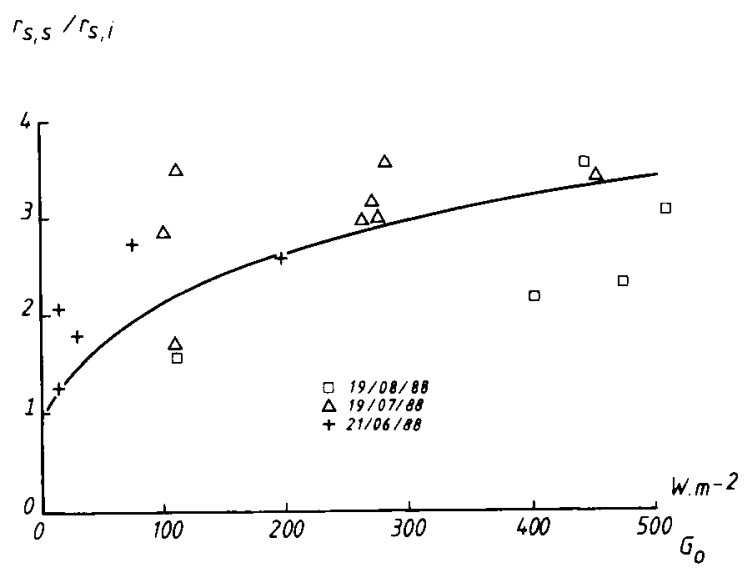

Fig 2. Évolution du rapport des résistances stomatiques des faces supérieure et inférieure de la feuille en fonction du rayonnement global mesuré sous la serre. 
Une courbe d'ajustement, du type :

$$
A=\log \left(\mathrm{a}+\mathrm{b} . G_{0}\right)
$$

a été utilisée pour représenter les variations de $A$ en fonction du rayonnement $G_{0}$. Les constantes a et $b$ ont été déterminées par ajustement avec les points expérimentaux et en forçant la courbe à passer par $A=1\left(r_{s, s}=r_{s, i}\right)$ pour $G_{0}=$ $0 \mathrm{~W} \cdot \mathrm{m}^{-2}$. Cette courbe est présentée sur la fig 2 , avec $a=2,7$ et $b=1 / 17,5$ et un coefficient d'ajustement $r^{2}=0,64$. Dans ce qui suit, nous présenterons les résultats concernant uniquement $r_{s, i}$ qui servira de référence et sera noté $r_{s}$.

L'évolution de la résistance stomatique en fonction de l'étage foliaire est illustrée sur la fig 3 , où $r_{s}$ a été mesuré à 3 niveaux $(0,5 \mathrm{~m}, 1,20 \mathrm{~m}$ et $1,90 \mathrm{~m}$, pour une hauteur totale de culture de $2,5 \mathrm{~m}$ ), pendant une période de transition jour/ nuit de $4 \mathrm{~h}$ à $9 \mathrm{~h}$ (TU). On observe que les valeurs de $r_{s}$ tout au long de cette période sont plus élevées pour l'étage le plus bas $(0,5 \mathrm{~m})$ et diminuent au fur et à mesure que l'on remonte dans la végétation. Des résultas obtenus sur d'autres journées montrent un comportement très voisin des étages inférieur et moyen. Les rapports entre résistances stomatiques aux différents niveaux restent à peu près constants dans le temps et la résistance stomatique diminue régulièrement vers l'intérieur du couvert. II existe donc un gradient vertical de résistance stomatique à l'intérieur du couvert, qui peut être lié, soit à des gradients verticaux de paramètres climatiques, soit à des caractéristiques physiologiques différents suivant l'étage, c'est-à-dire l'âge des feuilles.

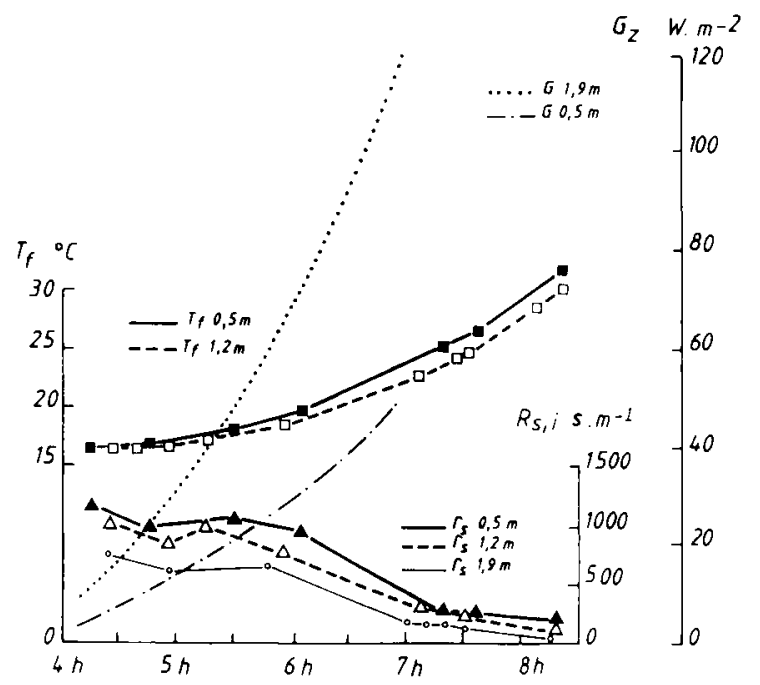

Fig 3. Évolution de la résistance stomatique de la face inférieure des feuilles et la température du couvert et du rayonnement $G_{(z)}$ reçu en fonction de l'heure du jour pour 3 étages du couvert $(0,5 \mathrm{~m}, 1,2 \mathrm{~m}, 1,9 \mathrm{~m}) ;(T, 1,9$ : données manquantes).
En dehors du cas net où l'augmentation de résistance stomatique peut être attribuée sans grand risque d'erreur à l'état de sénescence des feuilles (fig 4), la cause réelle du gradient de $r_{s}$ n'est pas de type physiologique. En effet, il paraît établi que l'âge physiologique de la plante n'a pas d'influence sur sa résistance stomatique tant que le processus de sénescence n'est pas installé (dégradation chlorophyllienne notamment), comme cela a été prouvé sur maïs (Turner, 1969), sur blé (Katerii, 1977) ainsi que sur luzerne (Katerji et al, 1983).

L'hypothèse à retenir est donc que le gradient vertical de résistance stomatique a son origine principalement dans l'existence d'un gradient d'un (ou plusieurs) des facteurs du climat. Les mesures de température d'air et de déficit de saturation, ainsi que celles de températures de feuilles (fig 3) montrent que les gradients verticaux de ces paramètres sont très faibles. La cause la plus probable est donc le gradient vertical de rayonnement de courte longueur d'onde, dû à l'atténuation du rayonnement lors de sa pénétration à l'intérieur du couvert. Cette hypothèse est conforme avec les valeurs du gradient de rayonnement observé à l'intérieur du couvert (fig 3) et avec les résultats d'observations effectués sur culture de luzerne (Katerji et al, 1983).

Un modèle multiplicatif, basé sur l'hypothèse que chaque facteur climatique ou hydrique participe de façon indépendante à l'établissement du niveau d'ouverture stomatique, a été proposé et utilisé dans la littérature (Jarvis, 1976; Avissar et Mahrer, 1982; Seginer, 1984; Stanghellini, 1987) :

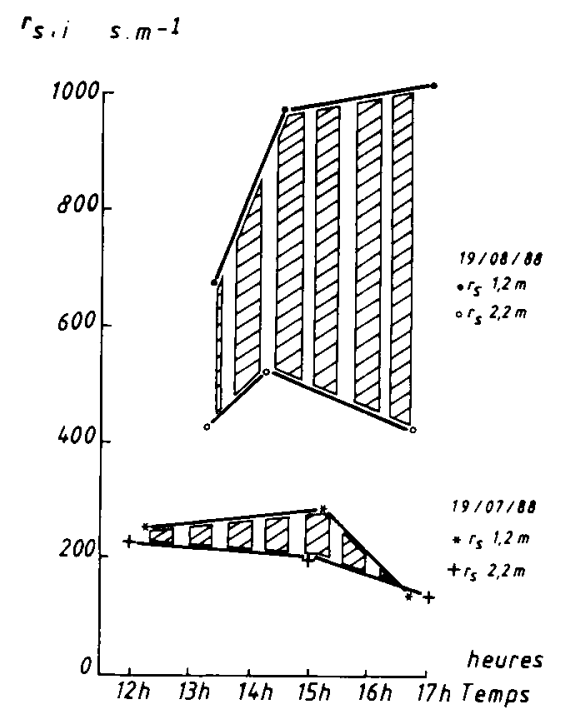

Fig 4. Évolution, en fonction de l'heure du jour, de la résistance stomatique de la face inférieure des feuilles pour deux étages du couvert $(1,2 \mathrm{~m}$ et $2,2 \mathrm{~m})$. Le 19 juillet 1988 : feuillage non sénescent; le 19 août 1988 : feuillage sénescent. 


$$
r_{s}(z)=r_{s, m} \cdot \prod_{k=1}^{n} f_{k}\left[x_{k}(z)\right]
$$

où $\pi$ représente l'opérateur multiplicatif, $f_{k}\left(x_{k}\right)$ est une fonction traduisant l'effet du facteur climatique (ou hydrique) $x_{k}(z)$, et $r_{s, m}$ est la résistance minimale au transfert de vapeur d'eau obtenue lorsque tous les facteurs $x_{k}$ sont à leur niveau optimal pour la transpiration.

Ce modèle multiplicatif suppose qu'il n'y a pas interaction entre les différents facteurs (Jarvis, 1976), ce qui n'est sans doute pas le cas pour au moins 3 facteurs climatiques : rayonnement, température et déficit de saturation. Dans le cas de nos essais, sans enrichissement en $\mathrm{CO}_{2}$ et avec une alimentation hydrique que l'on peut considérer comme proche de l'optimum, les facteurs $\mathrm{CO}_{2}$ et potentiel hydrique ne varient pratiquement pas. On considérera donc seulement les 3 fonctions suivantes : $f_{1}(G), f_{2}(T)$ et $f_{3}(D)$ où :

- $G\left(W . m^{-2}\right)$ est soit le rayonnement global incident au sommet de la culture, $G_{0}$, soit le rayonnement reçu au niveau de l'étage considéré, $G$ (z);

$-T\left({ }^{\circ} \mathrm{C}\right)$ est soit la température de l'air, $T_{a}$, soit la température foliaire, $T_{\mathbf{f}}$;

- $D$ (mbar) est le déficit de saturation rapporté soit à la température d'air : $D_{a}=e_{s}\left(T_{a}\right)-e_{a}$, soit à la température de feuille $: D_{f}=\mathrm{e}_{\mathrm{s}}\left(T_{f}\right)-e_{a}$;

$-e_{s}(T)$ étant la pression de vapeur saturante à la température $T$ et $e_{a}$ la pression actuelle de vapeur de l'air.

Dans notre cas, chaque fonction $f_{k}$ a été déterminée statistiquement à partir des mesures expérimentales de $r_{s}$, en utilisant des régressions non linéaires (algorithme de Marquardt, 1963; Draper et Smith, 1966) successivement appliquées à une variable $x_{k}$, puis aux autres variables, à partir de la variance résiduelle de la première itération.

En nous limitant à 2 paramètres explicatifs, $x_{1}$ et $x_{2}$ on $a$ :

$$
r_{s}=r_{s, m} \cdot f_{1}\left(x_{1}\right) \cdot f_{2}\left(x_{2}\right)
$$

II est alors possible d'identifier statistiquement les 2 fonctions partielles $f_{1}$ et $f_{2}$ à l'aide de 2 itérations successives.

Si $f_{1}$ est la première fonction à être identifiée, nous obtenons à l'issue de la première itération l'égalité suivantes:

$$
r_{s}=r_{s, m} \cdot t_{1}\left(x_{1}\right) \cdot e_{1}
$$

où $e_{1}$, conformément au modèle multiplicatif (2), exprime la variation résiduelle de $r_{s}$ au premier facteur et causée par le second facteur.

La fonction $f_{2}$ peut alors être identifiée en seconde itération à partir de l'égalité :

$$
e_{1}=f_{2}\left(x_{2}\right)
$$

avec

$$
e_{1}=\frac{r_{s}}{r_{s, m} \cdot f_{1}\left(x_{1}\right)}
$$

La fonction produit étant commutative, l'ordre des itérations est indifférent et nouspouvons également déterminer la fonction $f_{1}$ en seconde itération après avoir identifié $f_{2}$.

Dans un premier temps, seul le rayonnement global $G$ a été pris en compte. On a donc cherché une relation du type :

$$
r_{s}=r_{s, m} \cdot f_{1}(G)
$$

À partir des données de la littérature, 3 familles de fonction $f_{k}$ ont été testées:

- un modèle exponentiel (Avissar et al, 1985)

$$
f_{k}\left(x_{k}\right)=1+\left[\exp a_{1}\left(x_{k}-b_{1}\right)\right] \pm 1
$$

(exposant $<0$ pour $G,>0$ pour les autres facteurs climatiques)

- un modèle polynomial (Stanghellini, 1987) :

$$
f_{k}\left(x_{k}\right)=1+\frac{a_{1}}{\left(x_{k}-b_{1}\right) c_{1}}
$$

- un modèle homographique (Farquhard, 1978) :

$$
f_{k}\left(x_{k}\right)=\frac{1-a_{1} x_{k}}{1-b_{1} x_{k}}
$$

Après plusieurs essais de ces fonctions, nous avons retenu le modèle exponentiel qui minimise les écarts entre les valeurs observées et calculées, où $f_{1}$ est égal à :

$$
f_{1}=1+\left[\exp a_{1}\left(G-b_{1}\right)\right]^{-1}
$$

\section{Deux cas ont été étudiés :}

- on prend pour valeur de $G$ la valeur du rayonnement incident au sommet de la culture, $G_{o}$, quel que soit le niveau considéré; 
- on fait correspondre, à chacun des 3 étages de végétation, la quantité de rayonnement reçue au niveau ( $z$ ), calculée selon la loi exponentielle classique de décroissance de rayonnement :

$$
G(z)=G_{0} \cdot \exp \left(-K_{c} \cdot L A / \cdot \frac{z}{H}\right)
$$

où : $z=H-h, H$ étant la hauteur de la culture et $h$ la hauteur du niveau considéré. $K_{c}$, coefficient d'extinction du rayonnement (Goudriaan, 1977) est pris ici égal à 0,75 , d'après les résultats de Stanghellini (1983), qui suppose une distribution horizontale des feuilles, d'après ses mesures sur couvert de tomate.

On notera que, pour d'autres essais avec d'autres variétés, Stanghellini (1983) trouve une distribution conique, celle-ci étant en accord avec les mesures de Tchamitchian (1990).

Si nous comparons la résistance stomatique mesurée à celle calculée en prenant, soit le rayonnement reçu au-dessus du couvert, soit le rayonnement calculé reçu au niveau de la feuille nous observons que, dans le premier cas (fig 5), l'ajustement obtenu est assez moyen $\left(r^{2}=\right.$ 0,80 ), avec une forte dispersion. Dans le second cas, l'ajustement est nettement meilleur $\left(r^{2}=\right.$ 0,90 ), ainsi qu'on peut le constater sur la fig 5 . Une seconde variable a ensuite été prise en compte, dans l'itération réalisée à partir des résidus de la régression (3) :

- soit $D_{a}$ ou $D_{f}$,

- soit $T_{a}$ ou $T_{f}$

en utilisant le même type de fonction exponentielle pour ces variables, à savoir :

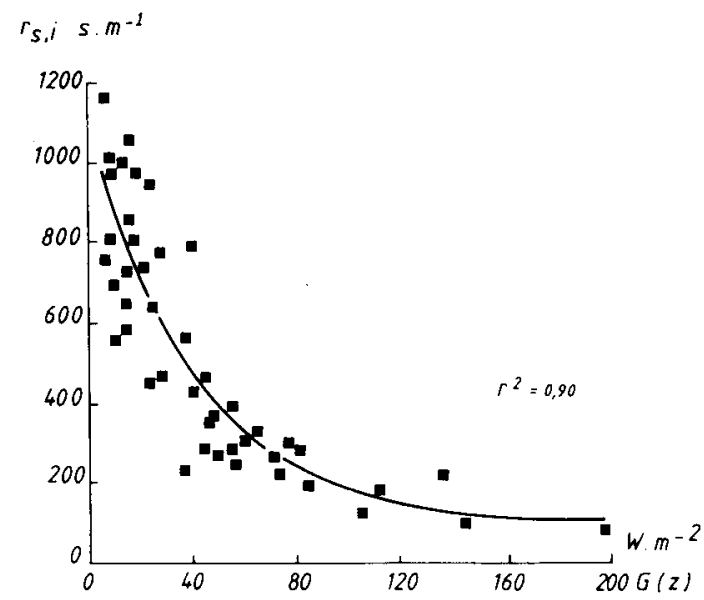

Fig 5. Évolution de la résistance stomatique de la face inférieure des feuilles en fonction du rayonnement reçu $G_{(z)}$ calculé au point de mesure en prenant en compte sa pénétration dans le couvert.

$$
f_{2}(D)=1+a_{2} \cdot \exp \left[b_{2}\left(D-D_{\max }\right)\right]
$$

ou :

$$
f_{2}(T)=1+a_{3} \cdot \exp \left[b_{3}\left(T-T_{\max }\right)\right]
$$

$$
\text { avec }: \begin{aligned}
T_{\max } & =30^{\circ} \mathrm{C} \\
D_{\max } & =10 \mathrm{mbar} \text { pour } D_{a} \\
& =30 \mathrm{mbar} \text { pour } D_{f} .
\end{aligned}
$$

Dans les deux cas de calcul de $G$, la régression entre d'une part la résistance stomatique corrigée de l'action du rayonnement (11) et d'autre part, soit la température, soit le déficit de saturation, est significative : un gain de variance important est observé lorsque l'on introduit le $2 e$ facteur climatique. Par contre, une itération supplémentaire (sur $D$, après régression sur $G$ et $T$, ou sur $T$, après régression sur $G$ et $D$ ) n'est plus significative (gain de variance inférieur à $5 \%$ ).

En résumé, 2 facteurs (dont $G$ obligatoirement) suffisent à décrire les variations de la résistance stomatique foliaire à un niveau donné dans un couvert de tomate: $G$ et $D_{a}$ (ou $D_{f}$ ), G et $T_{a}$ (ou $\left.T_{f}\right)$. Dans les 2 cas, les résultats sont meilleurs lorsqu'on utilise le rayonnement intercepté au niveau $z, G(z)$ plutôt que le rayonnement incident au sommet de la culture, $G_{o}$.

Pour expliquer le résultat obtenu ici, où les variations sont plurifactorielles, la matrice des corrélations entre les différences variables $\left(G_{0}, T_{f}\right.$, $\left.T_{a}, D_{a}\right)$ a été calculée. Le lien entre rayonnement et température d'air est hautement significatif $\left(r^{2}=0,87\right.$ entre $G_{0}$ et $T_{a}, r^{2}=0,82$ entre $G_{0}$ et $T_{f}$ ). II en va de même, mais à un degré moindre, entre rayonnement et déficit de saturation $\left(r^{2}=0,60\right.$ entre $G_{o}$ et $D_{f}, r^{2}=0,75$ entre $G_{0}$ et $\left.D_{a}\right)$. Ces fortes liaisons n'interviennent cependant pas dans la procédure suivie ici, puisque la variation de la résistance en fonction du rayonnement est de sens opposé à celle due à la température ou au déficit de saturation.

Par contre, la forte corrélation entre température et déficit de saturation $\left(r^{2}=0,86\right.$ entre $T_{f}$ et $D_{f}$ ) intervient directement, du fait du même sens de variation de $r_{\mathcal{S}}$ en fontion de ces 2 paramètres (même courbe exponentielle croissante). Ainsi, selon l'ordre d'itération, une grande partie de la variance de $r_{s}$ causée par la température peut statistiquement être expliquée par le déficit de saturation, et vice-versa.

Le tableau I donne les valeurs des paramètres des fonctions partielles, identifiées suivant la procédure statistique décrite plus haut et appliquée 
au jeu de données disponible de $r_{s}$ pour le cas $G$ $=G(z)$.

La figure 6(a-c) présente les évolutions de ces fonctions dans le cas où $G=G(z)$, accompagnées des points expérimentaux correspondants (résidus dans le cas des fonctions $f_{2}$ ).

\section{Modèle de transpiration du couvert}

\section{Détermination de la résistance moyenne équivalente du couvert}

À partir des mesures de $r_{s, i}$ (résistance inférieure), de la connaissance du rapport $A=r_{s, s} / r_{s, i}$ et d'une estimation de la résistance aérodynamique $r_{a}$, on peut définir une résistance totale $r_{t}$ pour un étage donné :

$$
r_{t}=\frac{r_{a}^{2}+A \cdot r_{s, i}{ }^{2}+(1+A) r_{\mathrm{a}} \cdot r_{s, i}}{2 \cdot r_{\mathrm{a}}+(1+A) r_{s, i}}
$$

Cette relation est obtenue en supposant une résistance $r_{a}$ en série avec les résistances inférieure et supérieure (fig 7), celles-ci étant considérées en parallèle (Lhomme et Katerji, 1988). L'expresssion de la résistance aérodynamique utilisée est celle proposée par Seginer, 1984 :

$$
\begin{array}{cc}
r_{\mathrm{a}} & =\rho \cdot C_{p} / h a \\
\text { avec ha } & =1,95 \cdot \frac{\left|T_{f}-T_{a}\right|^{0,25}}{l} \quad\left(\mathrm{~W} \cdot \mathrm{m}^{-1}\right) \\
&
\end{array}
$$

où / est une dimension caractéristique de la feuille.

Cette résistance $r_{t}$ peut être calculée pour chaque étage. Le flux de transpiration du couvert, $L_{c}$, sera donc la somme du flux $L_{j}$ de ces $n$ étages :

$$
L_{c}=\sum_{j=1}^{n} L_{j}
$$

avec :

$$
L_{j}=L A I_{j} \frac{\rho C_{p}}{\gamma} \cdot \frac{D_{t j}}{r_{t j}}
$$

- Si les valeurs de $L A l_{j}$ et $D_{f, j}$ sont supposées les mêmes pour chaque strate de végétation, ce qui est à peu près le cas pour un couvert de tomate bien développé, on aura donc :

$$
L_{c}=\frac{\rho C_{p}}{\gamma} L A l_{j} \cdot \mathrm{D}_{f, j} \cdot \sum_{j=1}^{n} \cdot \frac{1}{r_{t, j}}
$$

- Si $L A I_{c}$ représente la surface spécifique de feuilles de toute la culture et $D_{f}$ le déficit de saturation moyen dans le couvert, on peut définir une résistance moyenne, ou équivalente, $r_{e}$ telle que :

$$
L_{c}=\frac{\rho C_{p}}{\gamma} \cdot L A I_{c} \cdot \frac{D_{f}}{r e}
$$

Tableau I. Paramètres des fonctions partielles de variation de la résistance stomatique de la face inférieure des feuilles suivant les facteurs climatiques.

\begin{tabular}{lll}
\hline Variable & Coefficients & $r^{2}$ \\
\hline Rayonnement & $\begin{array}{l}a_{1}=5,10-2 \\
b_{1}=49 \pm 1\end{array}$ & 0,92 \\
$D_{a}$ Déficit de saturation de l'air & $\begin{array}{l}a_{2}=0,11 \pm 0,07 \\
D_{2}=0,34 \pm 0,05\end{array}$ & 0,85 \\
$D_{f}$ Déficit de saturation relatif à $T_{f}$ & $a_{2}=3,1 \pm 0,39$ & \\
$D_{f}=e_{s}\left(T_{a}\right)-e_{a}$ & $b_{2}=0,12 \pm 0,02$ \\
$T_{a}$ Température d'air & $a_{2}=0,31 \pm 0,13$ \\
$b_{2}=0,64 \pm 0,09$ & 0,90 \\
$T_{f}$ Température de feuille & $a_{2}=(4,3 \pm 2,3) 10-2$ & \\
& $b_{2}=0,38 \pm 0,04$ & 0,88 \\
\hline
\end{tabular}


s. $m^{-1}$
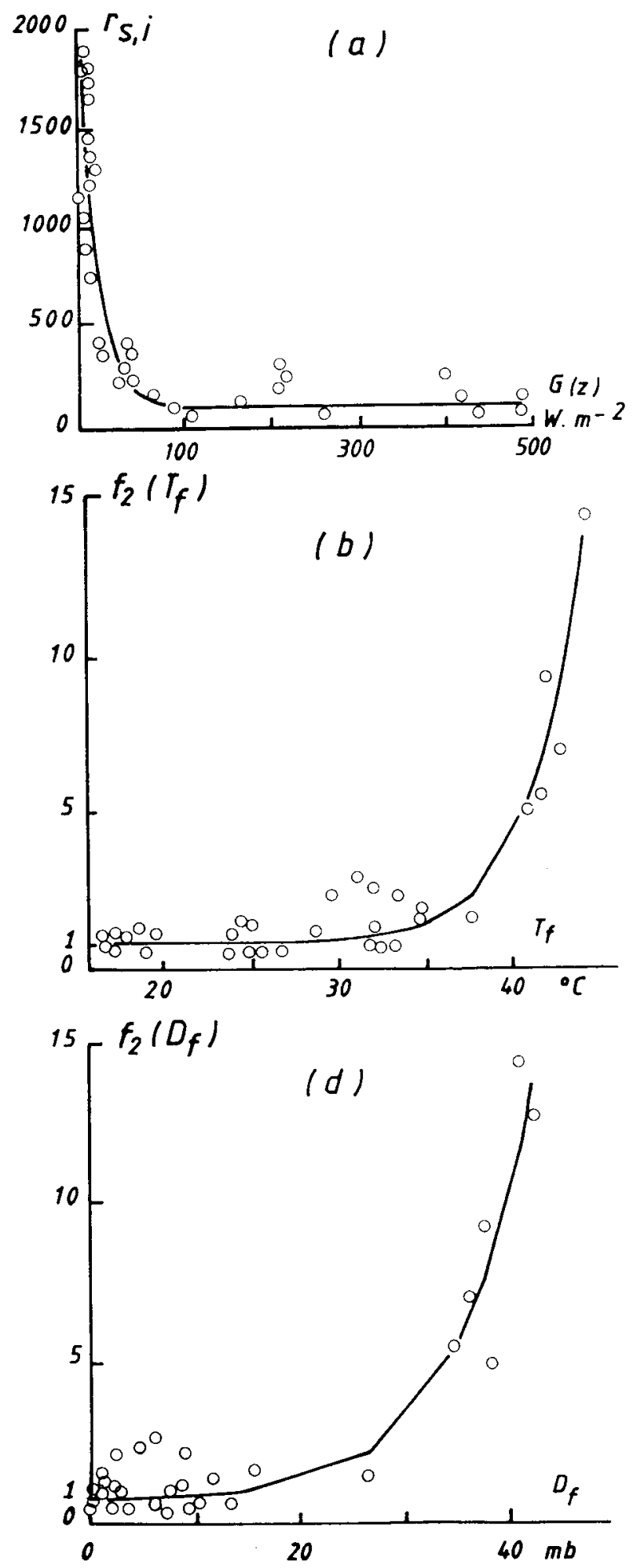
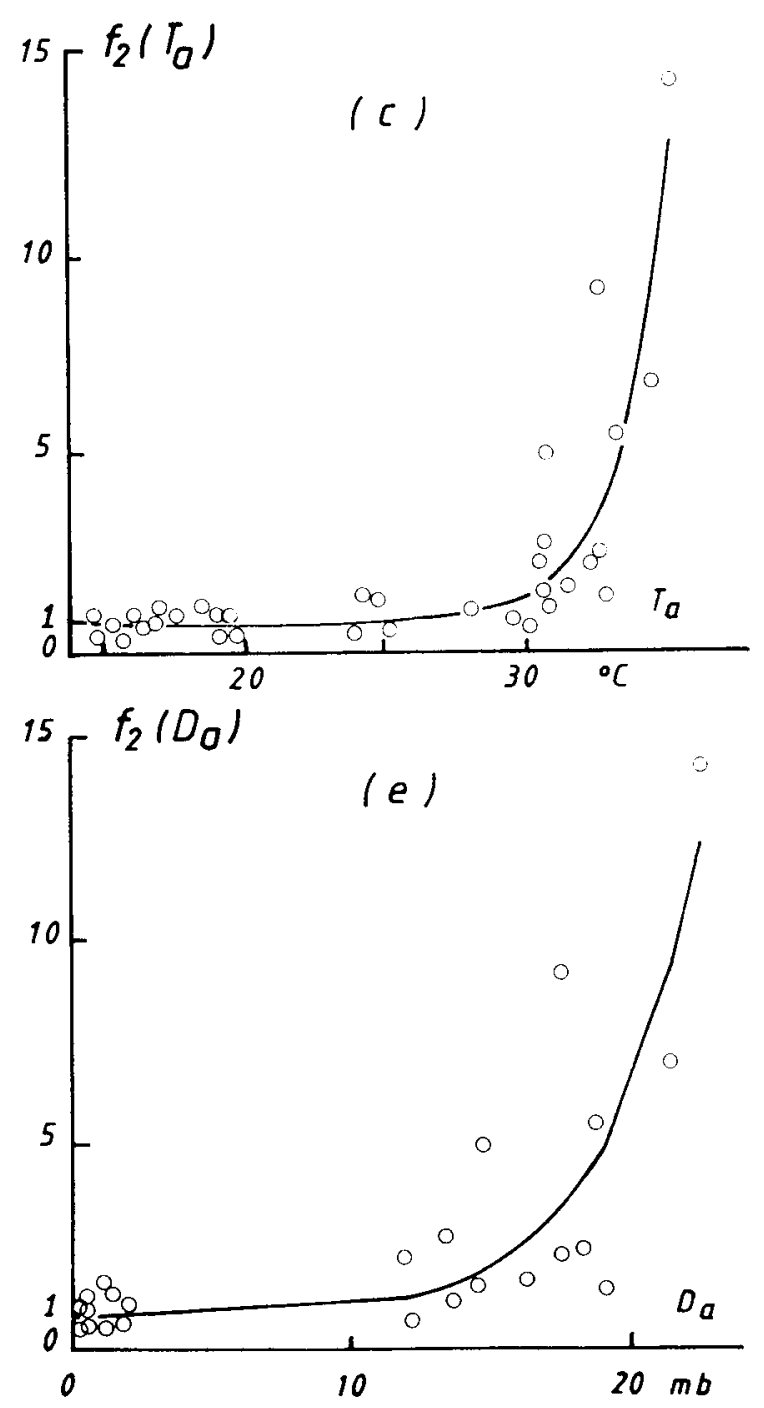

Fig 6. Points expérimentaux et fonctions d'ajustement des différentes fonctions partielles liant la résistance stomatique de la face inférieure des feuilles aux paramètres climatiques dans le cas où $r_{s, m}: 120{\mathrm{~s} . \mathrm{m}^{-1}}^{-1}$ : a) rayonnement transmis au niveau du point de mesure $G_{(z)}$; b) température des feuilles; c) température de l'air; d) déficit de saturation air-feuille; e) déficit de saturation de l'air. 


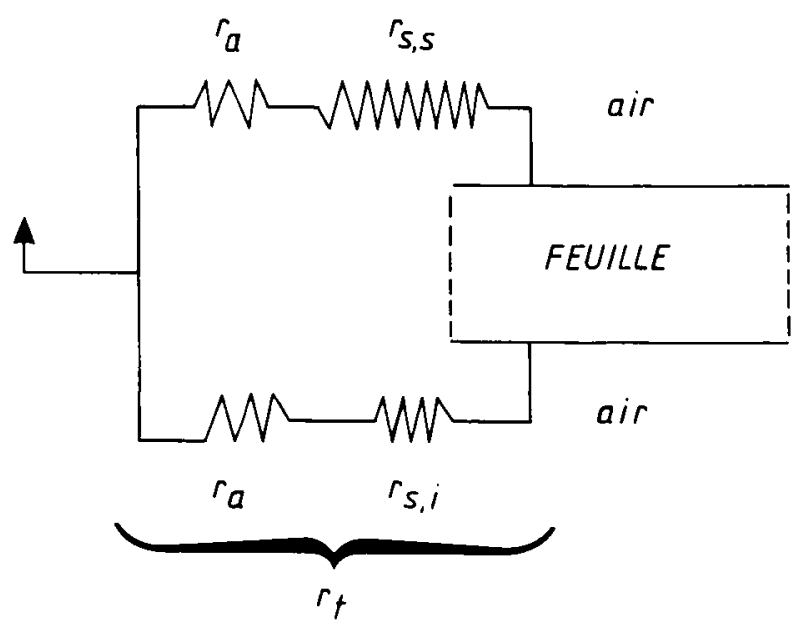

Fig 7. Schématisation de la résistance aux transferts de vapeur d'eau entre la feuille et l'air : $r_{a}=$ résistance aérodynamique, $r_{s, j}=$ résistance stomatique de la face inférieure de la feuille; $r_{s s}=$ résistance stomatique de la face supérieure de la feuille; $r_{t}=$ résistance totale (aérodynamique, et stomatique, face supérieure et inférieure).

avec $L A I_{c}=n . L A I_{j}$

$r_{e}$ sera donné par :

$$
r_{e}=\frac{1}{n} \cdot \sum_{j=1}^{n} \frac{1}{r_{t, j}}
$$

- Si $r_{t j}$ est supposée homogène pour chaque étage du couvert, on aura finalement $r_{\theta}=r_{t}$

Cette dernière condition est rarement vérifiée du fait de l'atténuation du rayonnement au cours de sa pénétration dans le couvert. On est donc amené à définir un rayonnement moyen $G_{m}$ reçu par le couvert :

$$
G_{m}=\frac{1}{H} \int \frac{H}{0} G(z) d z
$$

c'est-à-dire, en utilisant (11) :

$$
G_{m}=G_{0} \cdot\left(\frac{1-\exp \left(-k_{c} L A I\right)}{K_{c} \cdot L A I}\right)
$$

On a donc :

$$
r_{s}=r_{s, m} \cdot f_{1}\left(G_{m}\right) \cdot f_{2}\left(x_{2}\right)
$$

$x_{2}$ étant soit $D_{f}$ ou $D_{a}$, soit $T_{f}$ ou $T_{a}$

Cette démarche demeure valable s'il apparaît que la résistance stomatique moyenne de la face inférieure de la feuille calculée à partir du rayonnement moyen reçu par le couvert est la même que la moyenne des résistances stomatiques de chaque strate du couvert calculée à

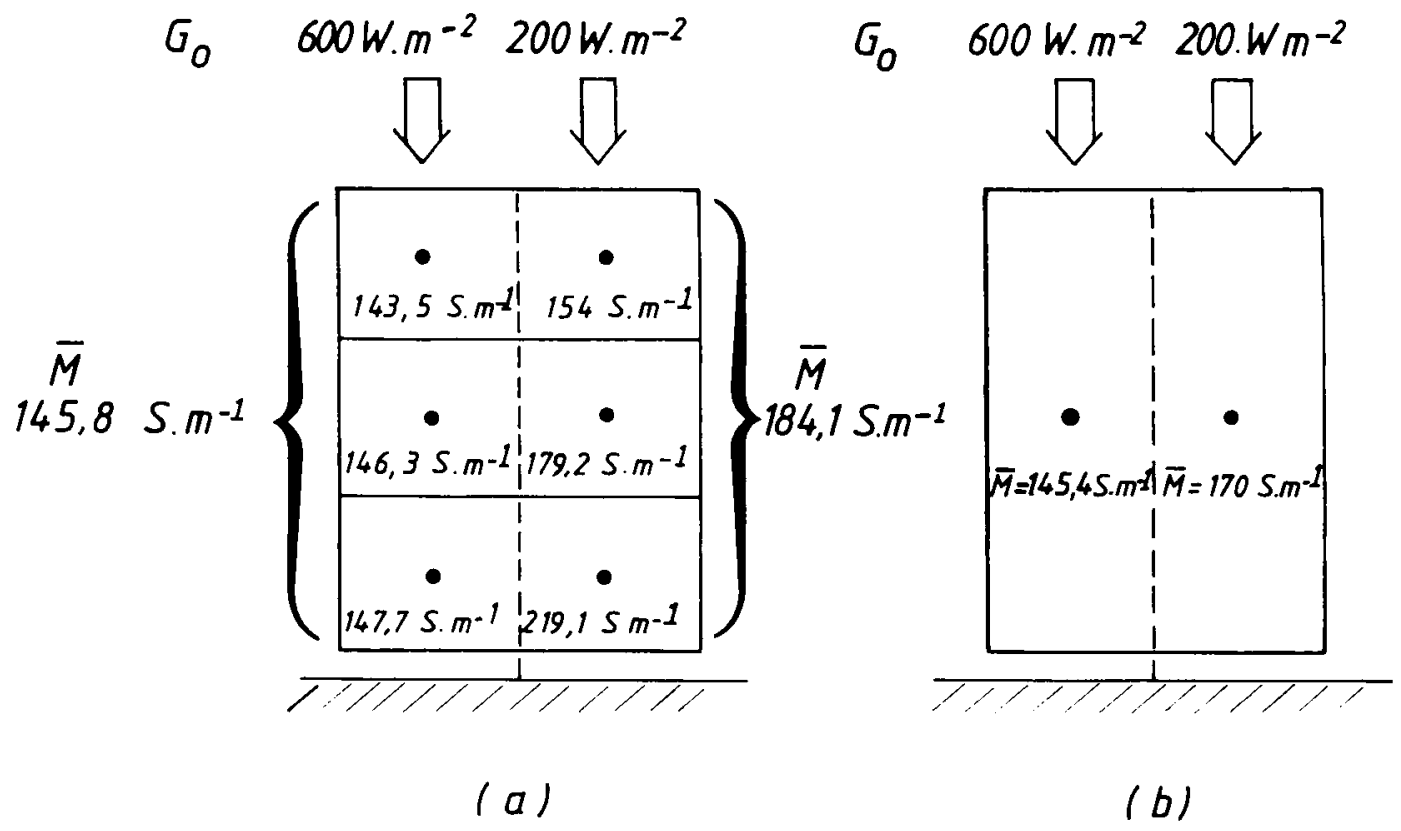

Fig 8. Valeurs de la résistance moyenne de la face inférieure d'un couvert de tomates $(L A l: 1,8)$ pour 2 valeurs du rayonnement global incident $G_{0}=600 \mathrm{~W} \cdot \mathrm{m}^{-2}, G_{0}=200 \mathrm{~W} \cdot \mathrm{m}^{-2}$. a) en considérant 3 strates de couvert, b) en considérant une seule strate de couvert. 
(a)

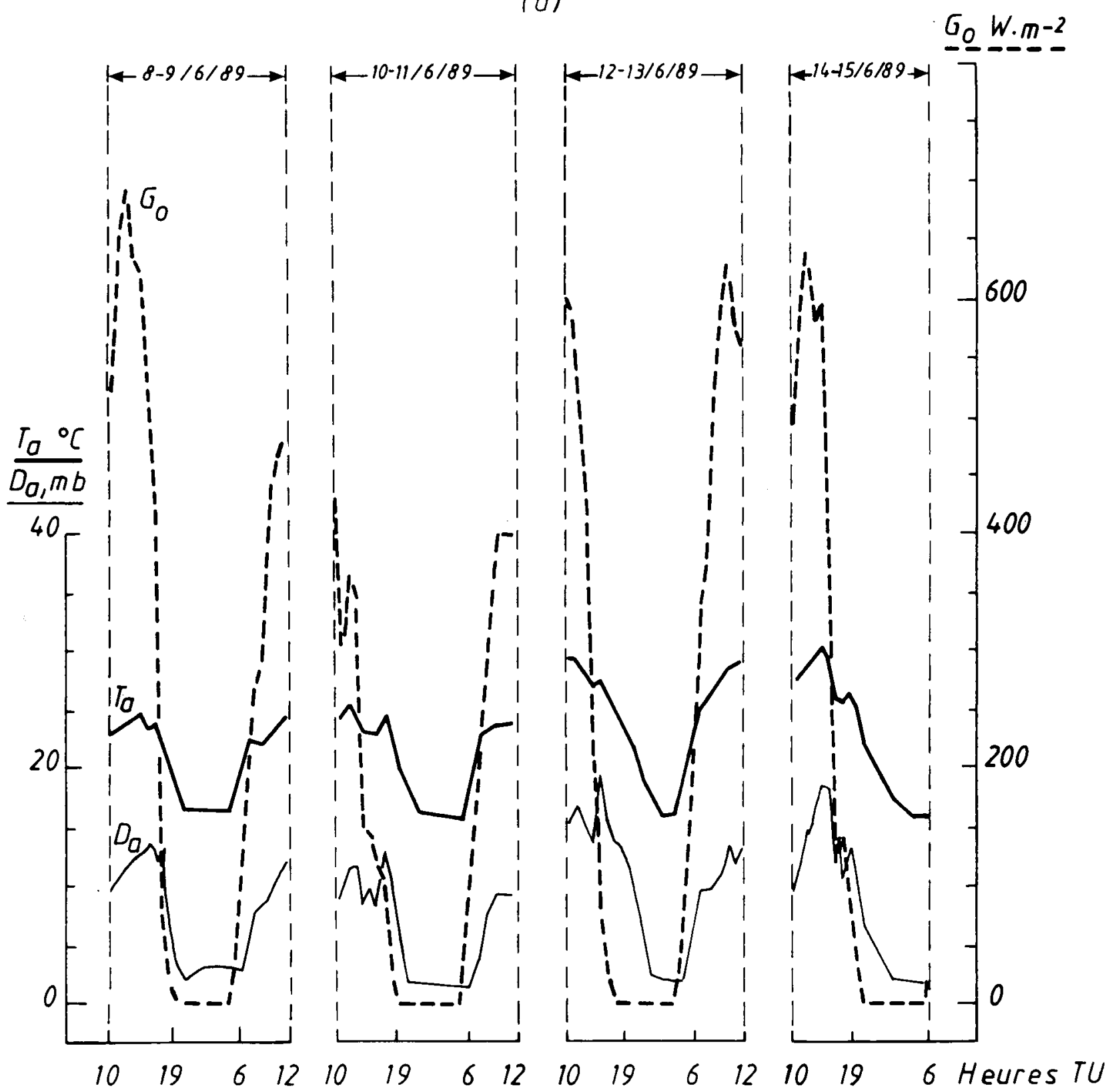

Fig 9. Comparaison des valeurs mesurées et calculées de la transpiration d'un couvert de tomate sous serre $(L A l=1,9)$ : a) Évoluvet, journées du 8 au 15 juin 1989); b) Evolution de la transpiration mesurée $L_{\text {mes }}$ à l'aide du lysimètre et de la transpiration $L_{c a l c 1}$

partir du rayonnement reçu par chacune de ces strates. Pour répondre à cette interrogation, nous avons effectué les 2 calculs (fig $8 \mathrm{a}, \mathrm{b}$ ) en prenant en compte soit une seule strate, soit 3 strates et avec 2 niveaux de rayonnement :

$$
G_{0}=600 W \cdot m^{-2} \text { et } G_{0}=200 W \cdot m^{-2} \text {. }
$$

Pour les rayonnements élevés $\left(G_{0}=600\right.$ W.m-2), les 2 approches aboutissent à des valeurs identiques de résistance stomatique moyenne $\left(145,8 \mathrm{~s} . \mathrm{m}^{-1}\right.$ pour 3 strates; $145,4 \mathrm{~s}$. $\mathrm{m}^{-1}$ pour une seule strate); par contre, pour une valeur faible de rayonnement $\left(G_{0}=200 \mathrm{~W} \cdot \mathrm{m}^{-2}\right)$, la régulation stomatique se manifestant de façon non linéaire (fig $6, a)$, on observe une légère différence de résistance stomatique moyenne (184 s.m-1 pour l'approche 3 strates, 170 s.m-1 pour l'approche 1 strate).

\section{Calcul de la transpiration du couvert}

Connaissant la résistance totale du couvert au transfert de vapeur d'eau, $r_{\theta}$, ainsi que la surface spécifique de feuille, $L A l$, le flux de transpiration du couvert peut être calculé de 2 façons : 
$L W . m-2$
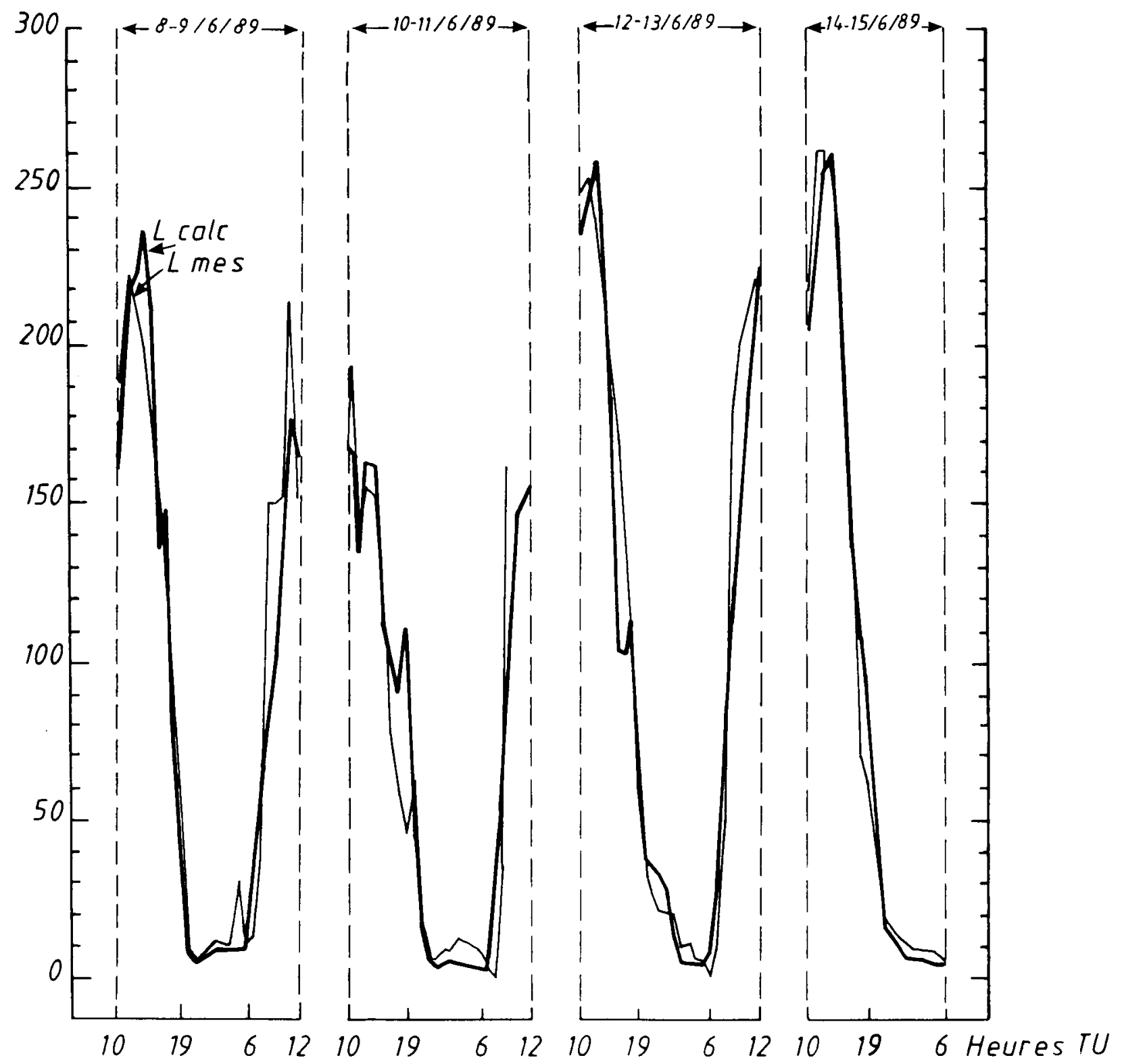

tion du rayonnement sous serre $\left(G_{0}\right)$, de la température d'air $\left(T_{a}\right)$ et du déficit de saturation de l'air $\left(D_{a}\right)$ mesurés sous abri (Montfacalculée à l'aide de la méthode combinatoire.

- directement à partir de l'expression du déficit de saturation air-feuille $D_{f}$ :

$$
L_{c}=\frac{\rho \cdot C_{p}}{\gamma} \cdot L A I_{C} \cdot \frac{D_{f}}{r_{e}}
$$

- par l'intermédiaire de la méthode combinatoire, connaissant le rayonnement absorbé par la culture : $G_{a b s}$ (cf annexe 2 ) et le déficit de saturation de l'air $D_{a}$

$$
L_{c}=\frac{\rho \cdot C_{p} \cdot L A I_{c} \cdot D a}{\delta \cdot r_{a e}+\gamma \cdot r_{e}}+\frac{\delta \cdot r_{a e} \cdot G_{a b s}}{\delta \cdot r_{a e}+\gamma \cdot r_{e}}
$$

$r_{\curvearrowright}$ étant la résistance aérodynamique de la feuille, les 2 faces étant considérées en parallèle : $r_{\mathscr{C}}=r_{d} / 2$.

Dans un premier temps, les mesures de transpiration acquises par pesée furent comparées aux sorties des 2 modèles (équations 23 et 24). Bien que, théoriquement, la méthode di- 
$L \operatorname{colc} W \cdot m^{-2}$

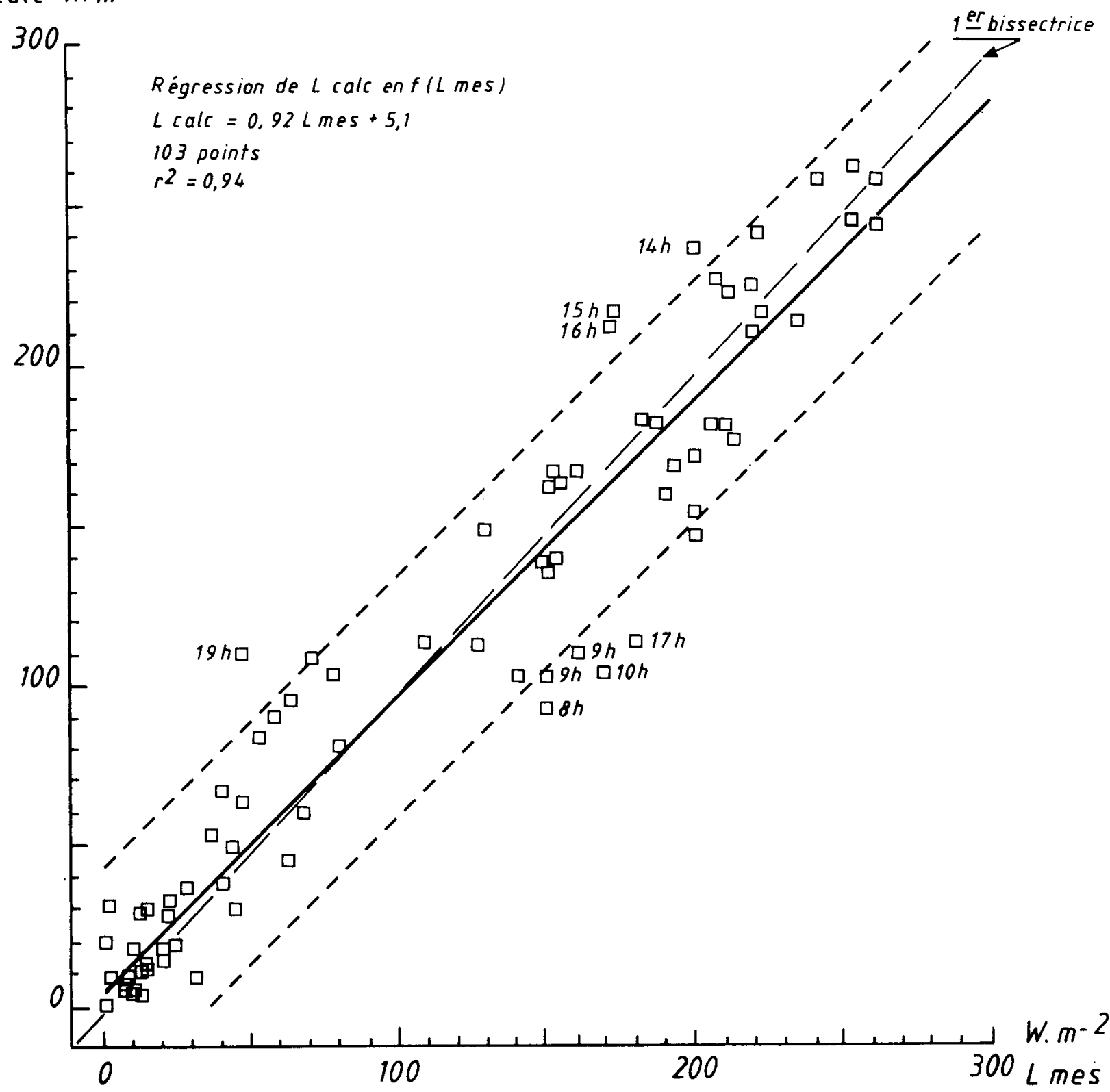

Fig 10. Régression statistique entre les valeurs horaires de la transpiration calculée $L_{c a l c}$ et mesurée $L_{\text {mes }}$ par le lysimètre. Les heures correspondant aux points situés hors de l'intervalle de confiance sont reportées sur la figure.

recte soit plus rigoureuse que la méthode combinatoire (qui fait appel à une approximation sur la valeur de la pente de la courbe de vapeur saturante en fonction de la température), nous avons observé une meilleure adéquation entre les mesures et les sorties du modèle faisant appel à la méthode combinatoire et cela, quelle que soit la méthode de mesure de $T_{f}$ : thermocouples disposés à 3 niveaux du couvert, ou radiothermomètre infrarouge Heiman KT17 (fig 1). La cause réside vraisemblablement dans les erreurs de mesure sur la température moyenne du feuillage, $T_{f}$, qui se répercutent sur le calcul du déficit de saturation, $D_{f}$, auquel fait appel l'équation (23). La température de feuille, étant difficilement mesurable à partir des systèmes de régulation du climat, nous avons donc sélectionné la seconde approche (dont les paramètres d'entrée $D_{a}$ et $G_{a b s}$ sont plus facilement accessibles à partir des systèmes commerciaux de régulation du climat) pour comparer les flux de transpiration mesurés à l'aide du lysimètre et calculés par l'intermédiaire de la méthode combinatoire. 
$L W . m^{-2}$
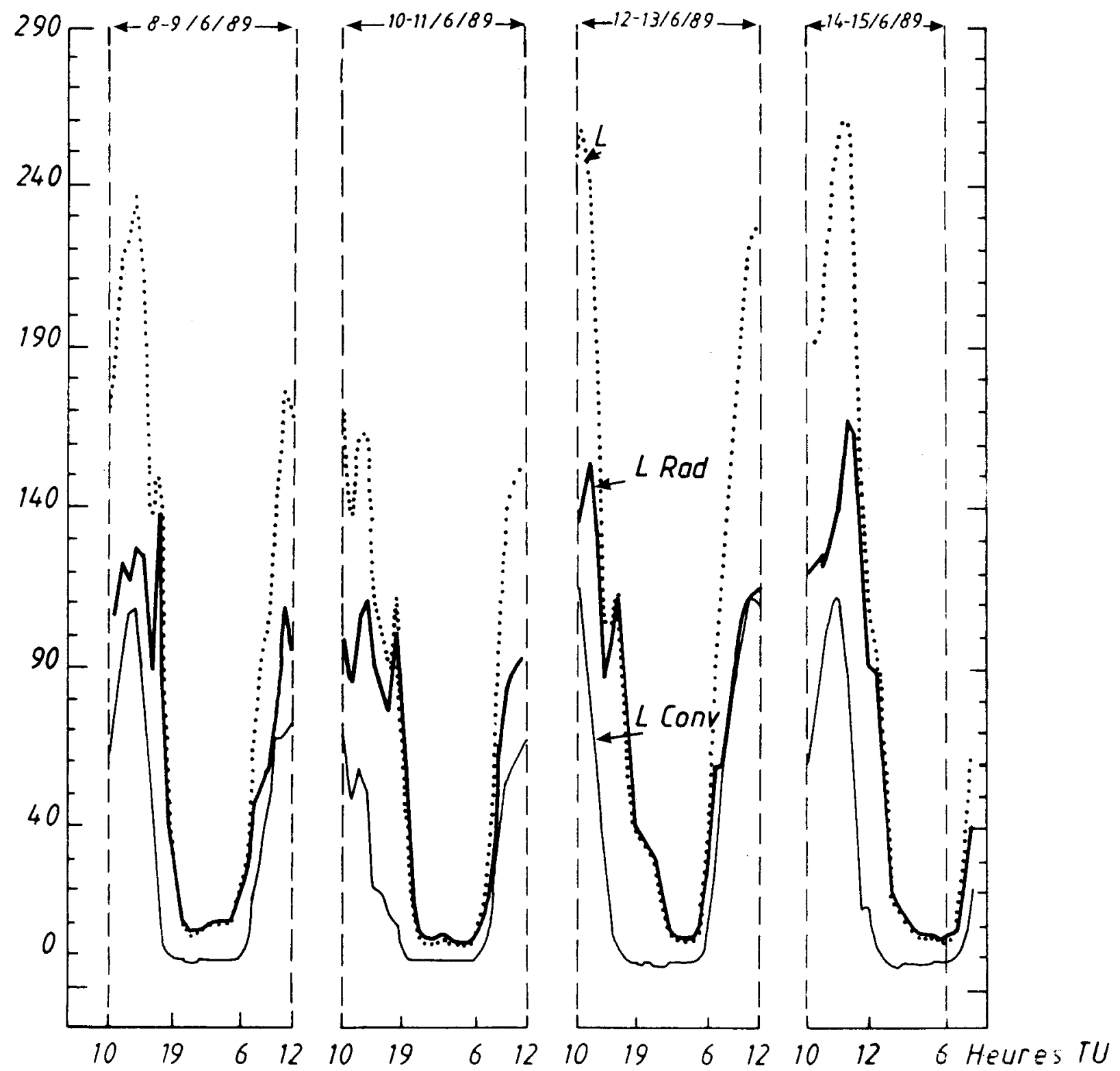

Fig 11. Évolution de la transpiration du couvert et des parts radiative et convective calculées à partir du modèle.

Les paramètres utilisés pour calculer $r_{a e}$ et $r_{\theta}$ sont ceux qui ont été identifiés en 1988 lors des essais réalisés à Alenya. La comparaison entre la transpiration mesurée et calculée porte sur des mesures réalisées en 1989 (printemps-été) à Montfavet. Les mêmes mesures n'ont donc pas servi à identifier les paramètres des modèles et à tester leur validité.

Nous pouvons illustrer cette comparaison par l'exemple des journées du 8 au 15 juin 1989. Les conditions climatiques $\left(G_{0}, T_{a}\right.$ et $\left.D_{a}\right)$ sont portées sur la figure 9a et les flux de transpiration calculés et mesurés sur la figure $9 b$.

On peut constater, malgré les fortes amplitudes de variation des flux, que les valeurs calculées reproduisent fidèlement les évolutions des valeurs mesurées au pas horaire. Sur le plan statistique, la droite de régression liant ces 2 grandeurs est très proche de la première bissectrice (fig 10). Une observation plus détaillée met en évidence que les plus fortes différences ne sont pas situées au niveau des minimums ou 
des maximums, mais plutôt dans les périodes intermédiaires entre le midi solaire et le lever ou coucher du soleil avec une sous-estimation de la transpiration le matin et une surestimation l'après-midi. Ce différences peuvent avoir une double origine :

- d'une part, une origine expérimentale : des mesures de rayonnement sont décalées par rapport au lysimètre (2-3 $\mathrm{m}$ de distance) ce qui entraîne un déphasage des ombres portées par les petits bois et les structures de la serre sur les plantes et sur la pile de mesure de rayonnement; - d'autre part, une origine liée aux simplications apportées dans la mise en œuvre du sousmodèle d'absorption du rayonnement par le couvert, notamment l'assimilation du rayonnement incident à un rayonnement entièrement diffus.

II nous semble donc que la prise en compte du rayonnement absorbé par la culture est certainement le point le plus sensible et le plus susceptible d'être amélioré de cette modélisation.

\section{DISCUSSION ET CONCLUSION}

Les expérimentations ont permis d'analyser l'évolution de la transpiration d'un couvert de tomates de serre en condition estivale et ses liaisons avec différents paramètres climatiques. Nous avons pu montrer que le choix des paramètres de résistance au transfert de vapeur d'eau était d'un poids considérable et nous nous sommes attachés à décrire le champ des résistances stomatiques en fonction:

- de l'étage du couvert,

- de la face supérieure ou inférieure de la feuille, - de l'influence des principaux paramètres climatiques.

Cette analyse a débouché sur la modélisation de la résistance stomatique de la face inférieure des feuilles en fonction des facteurs climatiques, au premier rang desquels le rayonnement semble le plus important et explique à lui seul l'essentiel de la régulation stomatique (en conditions d'irrigation non limitante). La résistance moyenne équivalente du couvert peut être alors déduite de la connaissance de la valeur des paramètres climatiques et il est possible de calculer la transpiration de la tomate sous serre à partir des paramètres du climat et de l'indice foliaire (LAl) et en se fixant uniquement comme paramètre physiologique la résistance stomatique mi- nimale $r_{s, m}$ de la face inférieure de la feuille de tomate.

La comparaison entre les sorties du modèle et le flux de transpiration mesuré montre que la prise en compte du couvert sous la forme d'une seule strate et la connaissance d'un nombre limité de variables d'état :

$G_{0}$ rayonnement au dessus du couvert,

$T_{a}$ température d'air,

$D_{a}$ déficit de saturation de l'air,

permet d'estimer de manière satisfaisante la transpiration d'un couvert de tomate en conditions de serre.

Bien que le sous-modèle de rayonnement absorbé par la culture puisse être amélioré, ce modèle de transpiration permet d'acquérir un gain de connaissance substantiel sur le déterminisme climatique de la transpiration si on le compare aux procédures encore communément utilisées sous serre (de Villèle, 1972), qui sont basées sur des corrélations statistiques du type :

$$
L_{c}=a \cdot G_{0}+b
$$

où seul le rayonnement est pris en compte.

Les calculs de la part radiative et advective de la transpiration établis à partir de la formule (24) (fig 11) montrent que cette dernière ne peut être négligée car elle représente environ $40 \%$ du total du flux de transpiration.

Par ailleurs, la forte corrélation observée entre rayonnement et déficit de saturation en conditions naturelles de plein champ (respectivement forts et faibles rayonnements associés aux forts et faibles déficits de saturation), qui explique la possibilité de s'affranchir de la prise en compte de $D_{a}$ dans la formule (25), n'existe plus à partir du moment où, comme cela se fait de plus en plus communément sous serre, on dispose de possibilités de contrôler séparement le rayonnement et l'humidité de l'air à travers les dispositifs de climatisation estivale (ombrage, aération, brumisation). Dans ce contexte, l'intérêt de prendre en compte le déficit de saturation et les variations de la résistance équivalente du couvert apparaît clairement. Cependant, une étude complémentaire demeure nécessaire pour déterminer les modalités pratiques d'identification des paramètres de résistance aux transferts d'eau (identification en ligne et/ou utilisation de modèle) avant de disposer d'une méthode qui soit opérationnelle dans le cadre du contrôle et de la régulation du climat et de l'irrigation dans des serres de production. 


\section{RÉFÉRENCES}

Avissar R, Avissar P, Mahrer Y, Bravdo BA (1985) A model to simulate response of plant stomata to environmental conditions. Agric For Meteorol 34, 2129

Avissar R, Mahrer Y (1983) Verification study of a numerical greenhouse microclimate model. Trans Am Soc Agric Eng 25, 1711-1720

Blanc D (1987) Les cultures hors-sol. INRA, Paris, $409 p$

Boulard T (1985) Étude du gisement de chaleur récupérable sur l'air d'une serre. Note Interne M/85/1 INRA, Station de Bioclimatologie, BP 91, 84143 Montfavet, $15 \mathrm{p}$

Chen J (1984) Uncoupled multilayer model for the transfer of sensible and latent heat flux densities from vegetation. Boundary-Layer Meteorol 26, 213225

Choudhury BJ, Monteith JL (1988) A four layer model for the heat budget of homogeneous land surface. QJR Meteorol Soc 114, 373-398

Draper NR, Smith H (1966) Applied Regression Analysis. Wiley and Sons, New-York

Farquhard GD (1978) Feedforward response of stomata to humidity. Aust J Plant Physiol 5, 787-800

Goudriaan J (1977) Crop micrometeorology: a simulation study. Simulation Monographs, PUDOC, Wageningen, $250 \mathrm{p}$

Gratraud J, Mekikdjian C, Guillaume P (1986) Serre Polylux, résultats des essais 1984-1986. Note Interne JG/JT CEMAGREF, Groupement de Montpellier, $13 p$

Jarvis PG (1976) The interpretation of the variations in leaf water potential and stomata conductance found in canopies in the field. Philos. Trans $R$ Soc Lond $B$ 273, 593-610

Kano A, Sadler EJ (1985) Survey of greenhouse models. J Agric Meteorol 41, 75-81

Katerji NB (1977) Contribution à l'étude de l'évapotranspiration réelle du blé tendre d'hiver. Application à la résistance du couvert en relation avec certains facteurs du milieu. Thèse Doct Ing, Paris VII, $121 \mathrm{p}$

Katerji NB, Perrier A (1985) Détermination de la résistance globale d'un couvert végétal à la diffusion de vapeur d'eau et de ses différentes composantes. Approche théorique et vérification expérimentale sur une culture de luzerne. Agric For Meteorol 34, 105-120

Katerji NB, Perrier A, Oulid-Aissa A B (1983) Exploration au champ et interprétation de la variation horizontale et verticale de la résistance stomatique : Agronomie 3, 847-856

Lhomme JP, Katerji N (1988) Analyse et formulation de l'évaporation à partir d'un modèle multi-couches. Études sur les transferts d'eau dans le système solplante-atmosphère. INRA, 259-274

Marquardt DW (1963) An algorithm for least squares estimation of non linear parameters. J Soc Indlan Appl Mathem 2, 431-441
Seginer I (1984) On the night transpiration of greenhouse roses under glass or plastic cover. Agric For Meteorol 30, 257-268

Stanghellini $C$ (1983) Radiation absorbed by a tomato crop in a greenhouse. Res Rep IMAG, Wageningen, $83,23 p$

Stanghellini C (1987) Transpiration of greenhouse crops, an aid to climate management. Thèse $P h-D$, IMAG, Wageningen, $150 \mathrm{p}$

Tchamitchian $M$ (1990) Photosynthèse d'une culture de tomate sous serre. Thèse de Docteur-Ingénieur, INP Toulouse $100 p$

Turner NC (1969) Stomatal resistance to transpiration in three controlled canopies, Crop Sci 9, 303-307

Varlet-Grancher C, Gosse G, Chartier M, Sinoquet $H$, Bonhomme R, Allirand JM (1989) Mise au point : rayonnement solaire absorbé ou intercepté par un couvert végétal. Agronomie 9, 419-439

de Villèle $O$ (1972) Water requirement of glasshouse crops: tentative estimation from solar radiation. Acta Hortic 35, 123-130

Yang W, Short TH, Fox RD, Bauerle WL (1989) The microclimate and transpiration of a greenhouse cucumber crop. Trans Am Soc Agric Eng 32, 21432149

\section{ANNEXE 1}

La détermination de la surface foliaire des plantes de tomate portée par le lysimètre a été obtenue en 2 étapes:

\section{1 re étape :}

Détermination d'une régression entre la surface de la feuille $s\left(\mathrm{~cm}^{2}\right)$ et le produit de sa plus grande longueur $L(\mathrm{~cm})$ par sa plus grande largeur $/(\mathrm{cm})$. Des prélèvements destructifs sur des plantes de bordure ont donné à la relation :

$S=0,5712$.(L.I) $-148,1$

$r^{2}=0,89$

$2 e$ étape :

La surface moyenne par plante est obtenue en sommant les surfaces élémentaires des feuilles déduites de la relation précédente à partir des mesures non destructives de $l$ et $L$ pour chaque feuille.

\section{ANNEXE 2. Calcul du rayonnement absorbé $G_{a b s}$ par un couvert de tomate dans les grandes et courtes longueurs d'onde}

Nous considérons tous les rayonnements comme étant diffus. 
Pour un couvert homogène

Connaissant :

$G_{0}$ : rayonnement incident de courte longueur d'onde au-dessus de la culture,

$R_{n}$ : rayonnement net au-dessus de la culture,

$R_{v}$ : rayonnement de grandes longueurs d'onde de la végétation calculé à partir de sa température,

$R_{s}$ : rayonnement de grandes longueurs d'onde du substrat calculé à partir de sa température de surface,

$\zeta_{v}$ : albédo du substrat, dans les courtes longueurs d'onde,

$\tau$ : transmittance du couvert en courtes longueurs d'onde,

$\tau_{L}$ : transmittance du couvert en grandes longueurs d'onde,

$\zeta_{v}$ : albédo de la culture.

Nous pouvons en déduire (fig 12) le rayonnement absorbé dans les courtes longueurs d'onde (Varlet Granchet et al, 1989) :

$$
G_{\mathrm{c}, \mathrm{abs}}=G_{\mathrm{o}}\left(1-\tau+\zeta_{s}-\zeta_{s \cdot} \tau^{2}-\zeta_{v}\right)
$$

ainsi que dans les grandes longueurs d'onde :

$R_{L, a b s}=R_{n}\left(1-\tau_{L}\right)+G_{0}\left(1-\tau_{L}\right)\left(\zeta_{V}+\zeta_{s} \tau^{2}-1\right)+R_{S}$ $\left(1-\tau^{2} L\right)+R_{V}\left(-1-\tau_{L}\right)$

En définitive, nous aurons :

$$
G_{a b s}=G_{c, a b s}+R_{L, a b s}
$$

\section{Prise en compte de l'absorption de la lumière par une culture en rangs}

Par rapport à une culture couvrante, il est nécessaire d'affecter le rayonnement absorbé par une culture en rangs d'un coefficient traduisant la perte d'interception lumineuse.

On émet l'hypothèse que la culture se présente sous la forme de parallélépipèdes, (pour nous, le double rang), de longueur infinie, de largeur $W$ et de hauteur $h$, l'interrang ayant pour largeur $p$ (fig 13).

Ainsi, Goudriaan (1977) considère que tout se passe comme si la largeur $W$ était augmentée d'une valeur $D w$, donnée par la formule suivante :
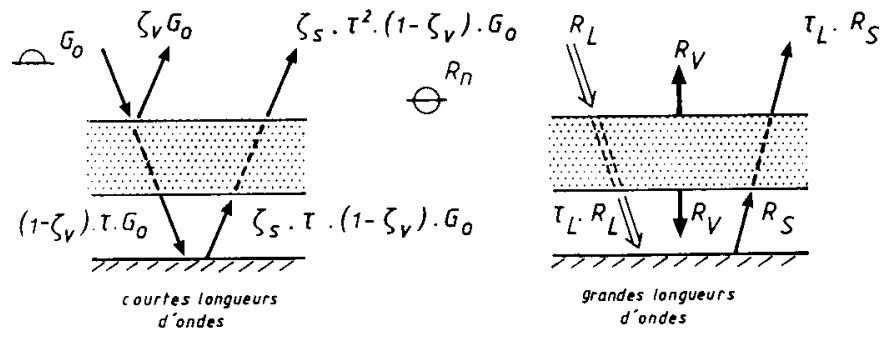

Fig 12. Schéma de la prise en compte du rayonnement de courtes et grandes longueurs d'onde absorbées par un couvert (cf signification des symboles dans le texte).

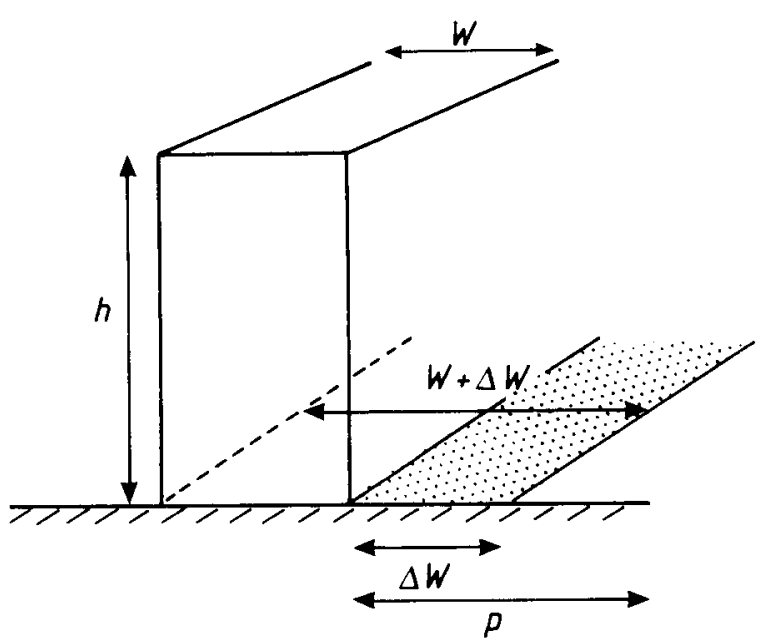

Fig 13. Schéma de prise en compte de l'absorption de la lumière par une culture en rangs ( $c$ signification des symboles dans le texte).

$$
D w=p+h-\left(p^{2}+h^{2}\right)^{0,5}
$$

La fraction $f(W)$ de rayonnement total susceptible d'être absorbée par la culture en rangs est alors :

$$
f(W)=(W+D w) /(W+p)
$$

Nous obtenons $f(W)=0,83$ en juin $(h=1,40 \mathrm{~m}$, $W=0,90 \mathrm{~m}, p=1,10 \mathrm{~m})$.

Pour les faibles $L A l$, lorsque le parallélépipède végétal n'est pas encore fermé (existence de trous), Stanghellini (1983) utilise la formule :

$$
f(W c)=\left(1-0,70 \cdot e^{-0,24 L A I}\right) \cdot f(W)
$$

Dans ce cas, $f(W c)$ est de l'ordre de 0,5 pour un $L A /$ variant de 2 à 3.

En conclusion :

$$
G_{a b s}=f(W c) \cdot\left(G_{c, a b s}+R_{l, a b s}\right)
$$

